Bioscientia Medicina: Journal of Biomedicine \&

Translational Research

Journal Homepage: www.bioscmed.com

\title{
Differences in Arteriovenous Fistula Maturation between Diabetes Mellitus and Non-Diabetes Mellitus in Chronic Renal Failure Patients in Padang Richard Santosa ${ }^{*}$, Raflis Rustam ${ }^{2}$, Vendry Rivaldy ${ }^{3}$
}

${ }^{1}$ Department of General Surgery, Faculty of Medicine, Andalas University/Dr. M Djamil Hospital, Padang, Indonesia

2,3Department of Vascular Surgery, Faculty of Medicine, Andalas University/Dr. M Djamil Hospital, Padang, Indonesia

\section{A R T I C L E I N F O}

Keywords:

Arteriovenous fistula

Diabetes mellitus

Chronic kidney failure

Hemodialysis

*Corresponding author:

Richard Santosa

E-mail address:

richardvaganza@gmail.com

\begin{abstract}
A B S T R A C T
Background: Arteriovenous fistula (AVF) is the preferred vascular access for hemodialysis (HD). Several factors can affect AVF maturity, such as diabetes. This study aims to determine the differences in the maturation of arteriovenous fistulas between diabetes mellitus and non-diabetes mellitus in patients with chronic kidney failure in Padang. Methods: This was a comparative cross-sectional study of patients with chronic kidney failure who underwent arteriovenous fistula surgery in Padang. The sampling technique in this study was consecutive sampling. The analysis was carried out using statistical analysis according to the existing data scale and using SPSS software. Results: This study involved 46 patients with chronic kidney failure who underwent arteriovenous fistula surgery in Padang, of which 23 patients with diabetes mellitus and 23 patients with non-diabetes mellitus. The diameter of the arteriovenous fistula between diabetes mellitus and non-diabetes mellitus in patients with chronic renal failure had a significant difference $(p<0.05)$. There was no significant difference in flow, depth, and maturation of arteriovenous fistulas in patients with diabetes mellitus and non-diabetes mellitus with chronic renal failure. Conclusion: There is no difference in the maturation of arteriovenous fistula between patients with diabetes mellitus and non-diabetes mellitus
\end{abstract}

All authors have reviewed and approved the final version of the manuscript.

https://doi.org/10.37275/bsm.v6i1.435

\section{Introduction}

Arteriovenous fistula (AVF) is the preferred vascular access for hemodialysis (HD). ${ }^{1}$ Based on the guidelines of the National Kidney Foundation - Kidney Disease Outcome Quality Initiative (NKF-K/DOQI), the location for arteriovenous fistula surgery on hemodialysis is: forearm (radiocephalic or distal arteriovenous fistula), elbow (brachiocephalic or proximal arteriovenous fistula), and arm (brachial artery-to-transposed basilic vein fistula). Determinants of the type and location of vascular access can be determined by Doppler ultrasound examination. ${ }^{2}$

The blood flow, diameter, and depth of the AVF can predict its clinical maturation. According to the 2019 NKF-K/DOQI guidelines, access can be defined as mature when the flow is $>600 \mathrm{ml} / \mathrm{min}$, the minimum venous diameter is $0.6 \mathrm{~cm}$, and the depth does not exceed $0.6 \mathrm{~cm}$. The time required ranges from 1 to 2 months from creating the AVF.2,3 The AVF primary failure rate is as high as $20 \%$ and has been reported to increase to $60 \%$. Several factors associated with AVF maturation failure are age $\geq 65$ years, female gender, uremia, diabetes mellitus, peripheral vascular disorders, and non-white race. ${ }^{4}$ Conte et al. reported that diabetes had a significant negative impact on AVF maturation. ${ }^{5}$ In contrast, the Sedlaceket study of 195 patients reported that diabetes mellitus was not associated with AVF maturation. 6

Diabetes mellitus accompanied by poor blood sugar 
control is an essential factor in primary AVF failure. ${ }^{7}$ The mechanism of the negative effects of AVF failure due to diabetes is not yet known. Diabetes mellitus will lead to the formation of atherosclerosis in blood vessels. 8 Although the mechanism is uncertain, one hypothesis relates to high blood glucose levels causing neointimal hyperplasia. It has been suggested that the most critical determinant of AVF maturation is probably the response of the feeding artery and draining vein to the increased shear stress that occurs after the creation of an arteriovenous anastomosis. An increase in shear stress, directly related to blood flow, invariably results in vascular dilatation. 7

Several studies have clearly demonstrated that an increase in arterial flow rate and shear stress secondary to distal AVF formation results in vascular dilatation and regression of neointimal hyperplasia.9,10 In addition, early hyperglycemia appears to be a more pronounced predictor of neointimal proliferation after carotid stent placement. 7 The complex differences regarding AVF maturation have made the authors interested in investigating further the differences in arteriovenous fistula maturation between diabetes mellitus and nondiabetes mellitus in patients with chronic renal failure in Padang.

\section{Methods}

This study design was an analytical study with a comparative cross-sectional design. The research subjects were all patients who underwent arteriovenous fistula surgery in Padang from August to November 2021. The collection of research subjects was carried out by a consecutive sampling process so that 22 research subjects with diabetes mellitus and 22 study subjects without diabetes mellitus underwent arteriovenous fistula surgery. This research has been approved by the Health Research Ethics Committee of Dr. M. Djamil Hospital Padang (No.380/KEPK/2021).

This study observed the level of maturation of the arteriovenous fistula in the form of diameter, flow, and depth of the arteriovenous fistula. Draining vein diameter in arteriovenous fistula was assessed using Mindray DC-N6 Ultrasonography (millimeter). The fistula arteriovenous flow velocity was assessed by
Mindray DC-N6 Doppler Ultrasonography (milliliters/min). The depth of the arteriovenous fistula was assessed by Mindray DC-N6 Doppler Ultrasonography (millimeters). An arteriovenous fistula is considered mature if it meets the following criteria: flow $>600 \mathrm{~mL} / \mathrm{min}$, a minimum venous diameter of 6 millimeters, and a depth not exceeding 6 millimeters.

Data analysis was carried out using SPSS version 25 software. Univariate analysis was used to see the distribution of data for each variable and then presented in tabular form. The data consists of the basic characteristics of the research sample. Categorical data are presented in terms of frequency, while continuous data is presented in terms of mean and standard deviation.

Before the bivariate analysis was carried out, the normality of the data was tested using the Kolmogorov Smirnov test or the Shapiro Wilk test. To assess the relationship between follow-up time and the level of maturation of the arteriovenous fistula (diameter, flow, and depth) an Independent T-test was performed. Data were analyzed at 95\% confidence intervals; if a p-value $<0.05$ was obtained, it could be concluded that there was a statistically significant relationship and difference in each hypothesis.

\section{Results}

Table 1 showed that the mean age of patients with diabetes was $55.22 \pm 9.71$ and non-diabetic was 50.39 \pm 10.37. Diabetes was controlled in $65.2 \%$ of patients and uncontrolled by $34.8 \%$. Smoking was mostly found in patients with diabetes, i.e., $47.8 \%$. The history of hypertension was $56.5 \%$ in patients with diabetes and $73.9 \%$ in non-diabetics. There was no difference in age, gender, controlled diabetes mellitus, hypertension, smoking, and type of surgery between diabetes mellitus and non-diabetes mellitus patients with chronic kidney failure $(\mathrm{p}>0.05)$.

Table 2 showed the mean arteriovenous fistula diameter in patients with diabetes mellitus, which was $6.35 \pm 1.13 \mathrm{~mm}$, while in patients with non-diabetes mellitus it was $7.05 \pm 1.01 \mathrm{~mm}$. Based on the Independent sample T-test, it was known that there was a difference in the diameter of the arteriovenous fistula between diabetes mellitus and non-diabetes 
mellitus in patients with chronic kidney failure $(\mathrm{p}<0.05)$. The mean arteriovenous fistula flow in patients with diabetes mellitus was 733.41 1320.35 $\mathrm{ml} / \mathrm{minute}$ while in patients with non-diabetes mellitus was 868.29 $\pm 272.99 \mathrm{ml} /$ minute. The mean arteriovenous fistula depth in patients with diabetes mellitus was $4.07 \pm 1.46 \mathrm{~mm}$ while in patients with nondiabetes mellitus was $3.60 \pm 1.21 \mathrm{~mm}$. There was no difference between arteriovenous fistula flow and depth between diabetes mellitus and non-diabetes mellitus in patients with chronic renal failure $(p>0.05)$.

Table 1. Characteristic of the subjects

\begin{tabular}{|c|c|c|c|}
\hline \multirow[b]{2}{*}{ Variable } & \multicolumn{2}{|c|}{ Chronic renal failure patients } & \multirow[t]{2}{*}{ p-value } \\
\hline & Diabetes mellitus ( $\mathrm{n}=23$ ) & $\begin{array}{l}\text { Non diabetes mellitus } \\
\qquad(\mathrm{n}=23)\end{array}$ & \\
\hline Age, mean \pm SD & $55.22 \pm 9.71$ & $50.39 \pm 10.37$ & $0.110^{a}$ \\
\hline Gender, $\mathrm{f}(\%)$ & & & $1.000^{\mathrm{b}}$ \\
\hline Male & $11(47.8)$ & $12(52.2)$ & \\
\hline Female & $12(52.2)$ & $11(47.8)$ & \\
\hline Diabetes mellitus, $\mathrm{f}(\%)$ & & & $\mathrm{n} / \mathrm{a}^{\mathrm{b}}$ \\
\hline Uncontrolled & $8(34.8)$ & 0 & \\
\hline Controlled & $15(65.2)$ & 0 & \\
\hline Hypertension, $\mathrm{f}(\%)$ & $13(56.5)$ & $17(73.9)$ & $0.353^{b}$ \\
\hline Smoking, $f(\%)$ & $11(47.8)$ & $9(39.1)$ & $0.766^{b}$ \\
\hline Surgical site, $\mathrm{f}(\%)$ & & & $0.330^{b}$ \\
\hline Right radiocephalic AVF & $1(4.3)$ & $2(8.7)$ & \\
\hline Left radiocephalic AVF & $14(60.9)$ & $9(39.1)$ & \\
\hline Left brachiocephalic AVF & $8(34.8)$ & $12(52.2)$ & \\
\hline
\end{tabular}

a, Independent sample T test; $\mathrm{b}$, Chi-square test; * $\mathrm{p}<0.05$ statistically significant

Table 2. Differences in arteriovenous fistula diameter, flow and depth between diabetes mellitus and non-diabetes mellitus in patients with chronic renal failure

\begin{tabular}{|c|c|c|}
\hline Chronic renal failure patients & $\begin{array}{l}\text { Diameter }(\mathrm{mm}) \\
(\text { mean } \pm S D)\end{array}$ & $\mathrm{p}$-value \\
\hline Diabetes mellitus & $6.35 \pm 1.13$ & $0.034 *$ \\
\hline Non diabetes mellitus & $7.05 \pm 1.01$ & \\
\hline Chronic renal failure patients & $\begin{array}{c}\text { Flow (ml/minute) } \\
\text { (Mean } \pm \text { SD) }\end{array}$ & p-value \\
\hline Diabetes mellitus & $733.41 \pm 320.35$ & $0.135 a$ \\
\hline Non diabetes mellitus & $868.29 \pm 272.99$ & \\
\hline Chronic renal failure patients & $\begin{array}{l}\text { Fistula depth }(\mathrm{mm}) \\
\quad(\mathrm{mean} \pm \mathrm{sd})\end{array}$ & P-value \\
\hline Diabetes mellitus & $4.07 \pm 1.46$ & $0.250 a$ \\
\hline Non diabetes mellitus & $3.60 \pm 1.21$ & \\
\hline
\end{tabular}

a, Independent sample $\mathrm{T}$ test; * $\mathrm{p}<0.05$ statistically significant

Mature arteriovenous fistulas were more common in non-diabetic chronic kidney failure patients (78.3\%) than diabetes mellitus (43.5\%), while immature arteriovenous fistulas were more common in chronic kidney failure patients with diabetes mellitus (43.5\%) compared to non-diabetes mellitus (21.7\%). 
Table 3. Differences in arteriovenous fistula maturation between diabetes mellitus and non-diabetes mellitus in patients with chronic renal failure

\begin{tabular}{|c|c|c|c|c|}
\hline \multirow[b]{2}{*}{ Maturation } & \multicolumn{2}{|c|}{ Chronic renal failure patients } & \multirow[b]{2}{*}{ Total } & \multirow[b]{2}{*}{ p-value } \\
\hline & $\begin{array}{c}\text { Diabetes Mellitus } \\
\text { (f/\%) }\end{array}$ & $\begin{array}{l}\text { Non diabetes melitus } \\
\text { (f/\%) }\end{array}$ & & \\
\hline Maturation & $13(56,5)$ & $18(78,3)$ & $31(67,4)$ & $0,208^{b}$ \\
\hline Immaturation & $10(43,5)$ & $5(21,7)$ & $15(32,6)$ & \\
\hline Total & $23(100,0)$ & $23(100,0)$ & $46(100,0)$ & \\
\hline
\end{tabular}

b, Chi-square test; *, $\mathrm{p}<0.05$ significant

\section{Discussion}

In this study, 46 patients with chronic renal failure underwent arteriovenous fistula surgery in Padang, of which 23 patients had diabetes mellitus, and 23 patients were non-diabetes mellitus. The mean age of chronic kidney failure patients with diabetes was 55.22 years, older than non-diabetic patients (50.39 years). Jin et al. conducted a study based on data from dialysis patients in Korea in 2016 showed the median age of diabetic patients in chronic kidney failure was 63.4 years, and the prevalence was higher in males than in females. 11

In this study, the prevalence of smoking in patients was $11 \%$ in diabetic patients with chronic renal failure and $9 \%$ in non-diabetic patients with chronic renal failure. The prevalence of hypertension in diabetic patients with chronic kidney failure was $56.2 \%$, while in non-diabetic patients with chronic kidney failure were $73.9 \%$. A cohort study conducted in China from November 2011 to April 2016 reported that hypertension (81.1\%) and smoking (48.86\%) were higher in the chronic renal failure group with diabetes than without diabetes. ${ }^{12}$

The diameter had a statistically significant difference $(p<0.05)$. The diameter of the arteriovenous fistula is a crucial factor in determining the maturity of the arteriovenous fistula. An observational study conducted in India from January 2014 to June 2015 reported the use of arteriovenous fistulas in patients with chronic renal failure with risk factors. The results of this study showed a significant relationship between arteriovenous fistula maturity and diabetes risk factors in patients $(\mathrm{p}<0.002) .13$

This study showed no significant difference between arteriovenous fistula flow and depth. Diabetes Mellitus in a patient will cause an increase in the formation of atherosclerosis which causes various lesions in the blood vessels. Diabetes will facilitate thrombus formation because of platelet aggregation and increased release of von Willebrand factor. The state of hyperglycemia in diabetic patients will cause interference with bioactive substances that cause lesions of the internal walls of blood vessels and make them less elastic. The pathogenesis of diabetes will lead to impaired blood flow. 14 The accumulation of fat in patients with diabetes and obesity can cause the arteriovenous fistula depth to be further below the skin surface. Increased adipose tissue under the skin surface will cause difficulty in accessing blood. 15 The difference between the results of this study and the existing theory may be due to the small study sample. This causes the results to be not statistically significant.

Tang et al. reported the results of a prospective observational study that arteriovenous fistula maturation did not have a significant difference in diabetic and non-diabetic renal failure patients. 16 Gordon et al. reported the same result, where the maturation and prognosis of arteriovenous fistula did not differ significantly between diabetic and nondiabetic patients. Diabetes is not one of the exclusion factors for the use of arteriovenous fistula access because diabetic patients have the same maturation results as non-diabetic patients. ${ }^{17}$

\section{Conclusion}

There was a statistical difference in the diameter of the arteriovenous fistula between diabetes mellitus and non-diabetes mellitus in patients with chronic renal failure $(\mathrm{p}<0.05)$. There was no statistical difference in 
AVF maturation between diabetic and non-diabetic patients with chronic kidney failure in Padang.

\section{References}

1. Ravani P, Palmer SC, Oliver MJ, et al. Associations between hemodialysis access type and clinical outcomes: a systematic review. J Am Soc Nephrol. 2013; 24(3): 465473.

2. Lok CE, Huber TS, Lee T, Shenoy S, Yevzlin AS, Abreo K, et al. Kidney disease outcomes quality initiave. AJKD. 2019; 75.

3. Quencer KB, Arici M. Arteriovenous fistulas and their characteristic sites of stenosis. AJR Am J Roentgenol 2015; 205(4): 726-734.

4. Lok CE, Allon M, Moist L, Oliver MJ, Shah H, Zimmerman D. Risk equation determining unsuccessful cannulation events and failure to maturation in arteriovenous fistulas (REDUCE FTM I). J Am Soc Nephrol. 2006; 17(11): 3204-3212.

5. Conte MS, Nugent HM, Gaccione P, Roy Chaudhury P, Lawson JH. Influence of diabetes and perivascular allogeneic endothelial cell implants on arteriovenous fistulare modeling. J Vasc Surg. 2011; 54: 1383-1389.

6. Sedlacek M, Teodorescu V, Falk A, Vassalotti JA, Uribarri J. Hemodialysis access placement with preoperative noninvasive vascular mapping: comparison between patients with and without diabetes. Am J KidneyDis. 2001; 38: 560-564.

7. Afsar B, Elsurer R. The primary arteriovenous fistula failure-a comparison between diabetic and non-diabetic patients: glycemic control matters. Int Urol Nephrol (2012); 44: 575-581.

8. Gołębiowski $\mathrm{T}$, et al. Vascular access in diabetic patients. Are these patients “difficult”? Postepy Hig Med Dosw (online), 2015; 69: 913-917.

9. Berceli SA, Davies MG, Kenagy RD et al. Flow induced neointimal regression in baboon polytetrafluoroethylene grafts is associated with decreased cell proliferation and increased apoptosis. J Vasc Surg 36: 12481255.

10. Qin F, Dardik H, Pangilinan A, Robinson J, Chuy J, Wengerter K. Remodeling and suppression of intimal hyperplasia of vascular grafts with a distal arteriovenous fistula in a rat model. J Vasc Surg. 2001; 34: 701-706.

11. Jin DC et al. Current characteristics of dialysis therapy in Korea: 2016 registry data focusing on diabetic patients. Kidney Res Clin Pract 2018 Mar;37(1): 20-29.

12. Zhang JJ, Yang L, Huang JW, Liu YJ, Wang JW, Zhang LX, et al. Characteristics and comparison between diabetes mellitus and non-diabetes mellitus among chronic kidney disease patients: a cross-sectional study of the chinese cohort study of chronic kidney disease (C-STRIDE). Oncotarget. 2017; 8(63): 106324-32.

13. Venkatnarayanan R, Dogra PM, Bavdekar R, Singh SK, Mondal AK. Primary failure of autogenous arteriovenous fistula: critical analysis. Indian J Nephrol. 2020; 30(6): 382390.

14. Yan Y, Ye D, Yang L, Ye W, Zhan D, Zhang L, et al. A meta-analysis of the association between diabetic patients and AVF failure in dialysis. Renal Failure. 2018; 40(1): 379-83.

15. Fontenol DT, Tanious A, Arhuidese I, Chauhan YM, Stafford AM, Illig KA. Arteriovenous access superficialization: a new technique and review of options. Annals of Vascular Surgery. 2020; 69: 43-51.

16. Tang WJ, Adnan AS, Salleh MSM, Saad AZM. Microcalcification in the arterial wall and its relationship to the ultrasound criteria of maturation of the arteriovenous fistula. The Journal of Vascular Access. 2019;20(1):4651.

17. Gordon A, et al. Diabetes should not dissuade arteriovenous fistula formation. British Journal of Diabetes. Br J Diabetes 2016; 16 : 119-122. 